\title{
Development and initial testing of the Person-Centred Health Care for Older Adults Survey
}

\author{
Briony Dow, ${ }^{1}$ Marcia Fearn, ${ }^{1}$ Betty Haralambous, ${ }^{1}$ Jean Tinney, ${ }^{1}$ Keith Hill ${ }^{2}$ \\ and Stephen Gibson ${ }^{1}$ \\ ${ }^{1}$ National Ageing Research Institute, Poplar Road, Parkville, Victoria, Australia \\ ${ }^{2}$ School of Physiotherapy, Curtin University, Kent Street, Bentley, Western Australia, Australia
}

ABSTRACT

Background: Health services are encouraged to adopt a strong person-centered approach to the provision of care and services for older people. The aim of this project was to establish a user-friendly, psychometrically valid, and reliable measure of healthcare staff's practice, attitudes, and beliefs regarding person-centered healthcare.

Methods: Item reduction (factor analysis) of a previously developed "benchmarking person-centred care" survey, followed by psychometric evaluations of the internal consistency reliability and construct validity, was conducted. The initial survey was completed by 1,428 healthcare staff from 17 health services across Victoria, Australia.

Results: After removing 17 items from the previously developed "benchmarking person-centred care" survey, the revised 31-item survey (Person-Centred Health Care for Older Adults Survey) attained eight factors that explain $62.7 \%$ of the total variance with a Cronbach's $\alpha$ coefficient of 0.91 , indicating excellent internal consistency. Expert consultation confirmed that the revised survey had content validity.

Conclusions: The results indicated that the Person-Centred Health Care for Older Adults Survey is a userfriendly, psychometrically valid, and reliable measure of staff perceptions of person-centered healthcare for use in hospital settings.

Key words: older people, person-centered care, hospital setting, staff perception, survey

\section{Introduction}

The world's population aged 60 years and older is expected to more than triple from 600 million to 2 billion between 2000 and 2050 (Department of Economic and Social Affairs: Population Division, 2002). As the population ages, the number of older people needing healthcare is increasing and more older people are using health services. In Victoria, Australia, people older than 65 years were reported to be using more than $49 \%$ of all inpatient hospital days in 2007-08 (Australian Institute of Health and Welfare, 2009) and in the United Kingdom in 2000, two-thirds of acute hospital beds were occupied by patients aged 65 years and older (Department of Health, 2000, as cited in Bridges et al., 2009). In a systematic review of qualitative research focused on older people's and

Correspondence should be addressed to: Dr Briony Dow, National Ageing Research Institute, PO Box 2127, Royal Melbourne Hospital, Parkville, Victoria 3050, Australia. Phone: +61 (3) 8387 2639; Fax: +61 (3) 83872153. Email: b.dow@nari.unimelb.ede.au. Received 4 Jan 2013; revision requested 26 Jan 2013; revised version received 7 Mar 2013; accepted 10 Mar 2013. their relatives' views on and experiences of acute care, Bridges and colleagues (2009) concluded that older people and their relatives value approaches to care that are relational in nature, where they have a reciprocal relationship with staff, where staff get to know them as individuals and understand what is important to them, where they can participate in decision-making and have information presented to them in ways that respond to their individual needs (for example, taking into account cognitive impairment or communication difficulties). For this reason, health services need to ensure that they have an environment that is appropriate for the older person and their specific care needs and have a culture that places the older person at the center of their own care.

To improve the experience of older people in hospitals in Victoria, the then Victorian Government Department of Human Services (DHS) launched the Improving Care for Older People (ICOP) policy in 2003 (Victorian Government Department of Human Services, 2003). The aim of this policy was to improve health services for older people and their 
carers and for people with complex care needs. The policy encouraged health services to

1. adopt a strong person-centered approach to the provision of care and services,

2 . better understand the complexity of older people's healthcare needs, and

3. improve integration of care.

The National Ageing Research Institute (NARI) was commissioned by DHS (now Department of Health (DH)) to find or develop a tool that could be used to measure staff attitudes and practices in relation to person-centered care, and to develop educational resources to support person-centered care, such as best practice case examples and a website with links to international initiatives. This paper reports on the development and testing of the measurement tool.

DHS defined person-centered care as "treatment and care ... that puts the person at the center of their own care and considers the needs of the older person's carers" (Victorian Government Department of Human Services, 2003). The NARI team conducted a literature review that aimed to further define personcentered healthcare, to document any evidence of its effectiveness, and to locate an appropriate measure of person-centered healthcare for use in the ICOP initiative. The literature search included the following key words: person-centered practice, person-centered care, client-centered practice, client-centered care, consumer-focused practice, consumer-focused care, patient-centered care, and client goal setting. The Cochrane Library and the Pubmed and Ovid databases (including Cinahl, Psychlit, and Medline) were searched. Literature published prior to 1995, literature on pediatric clients, and literature that considered adults younger than 70 (unless they had complex care needs such as adults with post-traumatic brain injury or stroke) were excluded. In addition, reports that included direct feedback from clients and/or carers about their experience of healthcare were also included. All four levels of evidence determined by the National Health and Medical Research Council (1999) and qualitative research reports were included in this review.

The literature review identified numerous definitions of person-centered care, including one from the United States Agency for International Development (USAID 1999, as cited in Harkness, 2005, p. 9), and one from Canadian occupational therapists (Law et al., 1995). All of the definitions, including the one by DHS, place the patient, client, or person at the center of healthcare and identify the consideration of their needs and wishes as paramount.
Five principles of person-centered care were identified in the literature:

1. Getting to know the patient or client as a person (holistic approach as well as individual approach),

2. Sharing of power and responsibility (patient or client as expert in their own health, sharing of decision-making, information, the idea of common ground),

3. Accessibility and flexibility (of service provider as a person and of the services provided),

4. Coordination and integration (consideration of the whole experience from the point of view of the service user), and

5. Having an environment that is conducive to personcentered care (supportive of staff working in a person-centered way and easy for service users to navigate).

The literature also described three main approaches to evaluating person-centered care:

1. Evaluate the person-centeredness of a single clinical intervention or the work of a single clinician from the point of view of a trained observer or assessor, or through a self-report instrument, usually completed by the patient,

2. Assess client satisfaction with the service as a whole, including its person-centeredness, and

3. Evaluate the extent of person-centered practice within a health setting using a benchmarking tool or observation (Dow et al., 2006).

The third approach was selected as the most appropriate to evaluate person-centered care within Victorian health services as the purpose of the tool was to assist staff to reflect on their own practice, either as individuals or as part of a team, educate them about person-centered practice, and give direction for areas that they could work to improve.

The literature review revealed that there were no previously published measures of person-centered care in health settings at the time, so the NARI team developed the "benchmarking person-centred care" survey.

\section{Aims}

The aims of this project were to

1. conduct a psychometric evaluation of the properties of the initial "benchmarking person-centred care" survey,

2. investigate the "benchmarking person-centred care" survey as a psychometrically valid and reliable measure of current practice and attitudes or beliefs in relation to person-centered care from the point of view of healthcare staff, and

3. increase the ease of use of the "benchmarking person-centred care" survey by reducing the number of items. 


\section{Methods}

\section{Ethics}

Ethics approval was obtained from all the participating health service human research ethics committees.

\section{Survey development}

The original survey developed by the NARI team was based on key elements identified in the literature (Dow et al., 2006), and on advice from older people themselves (via consultative focus groups) as to what they viewed as important aspects of person-centered care.

The five key principles in person-centered care identified in the literature were used as the starting point for the survey. Questions addressing each of these key principles in person-centered care were developed by the NARI team, which included research staff with clinical expertise. The draft survey was then reviewed by the project Expert Advisory Group, which consisted of experts in the healthcare field (including geriatricians, nurses, policy makers, and allied health personnel with both academic and clinical knowledge of care of older people in hospital), healthcare staff (including nurses, medical practitioners, and allied health staff currently working with older people in assessment and treatment wards), and representatives of carer and consumer advocacy groups. They suggested that the survey needed to include questions about items that are important to older people, and that greater consumer input on the survey development was required. As there was very little published literature on older people's views on person-centered healthcare, two focus groups were conducted with older people to confirm that what was included in the survey was relevant to them and to add anything that they thought was missing. Consulting with older people, advocacy groups, healthcare staff, and academics with expertise in the area was considered to be the best way of validating the items derived from the literature by the research team, as it enabled triangulation of views (Docherty, 2000). Furthermore, it was considered important that the survey development involved a partnership between researchers and older people, as this was the main concept to emerge from our literature review and we felt that the research process should be consistent with a person-centered approach.

The 20 focus group participants (four male) were all older (over 65 years of age) NARI volunteers (that is, people who have expressed an interest in participating in research and placed their contact details on a register of volunteers), who had experienced a hospital admission themselves or were caring for someone who had been in hospital on one or more occasions in the past two years. They were asked about their experiences of hospital and what they thought constituted good care. They were then asked to review a draft of the survey and to identify anything they thought was missing, and whether they thought the questions represented what was important to them. Results of the focus groups confirmed that the questions already developed were important to older people. Another section was added that contained questions about aspects of person-centered care considered important to the focus group participants but not in the initial survey, including questions about privacy, parking and access, and hot food being served hot.

The initial benchmarking survey based on the literature and focus group findings was a 48 -item survey divided into six sections.

1. getting to know the older service user (seven items),

2. sharing power and responsibility (eight items),

3. service flexibility and accessibility (eight items),

4. making sense of services for the older service user (seven items),

5. the working environment facilitates person-centered practice (nine items),

6. concerns expressed by older people (nine items).

The survey questions explored respondents' attitudes and beliefs and current practice in relation to person-centered care. Person-centered care practice is likely to be influenced by staff attitudes and beliefs and we felt it important to identify where future educational and practice change interventions should be directed. For example, staff may need education that challenges negative attitudes and beliefs about older people or they may require specific training in goal setting with older people. As one of the aims of the survey was to benchmark current practice and identify areas where health services could improve their personcentered practice, both attitudes and beliefs and practices were included in the survey. The response format for each question was a 5-point Likert scale, ranging from 1 (strongly disagree) to 5 (strongly agree) for the attitude and belief questions or 1 (never) to 5 (always) for the practice questions.

\section{Survey dissemination and completion}

The survey was disseminated to approximately 4,018 staff in 17 Victorian health services in 2005 . Respondents were provided with two options of completing the survey, either online through a secure website or paper based. Each health service employed a key implementation contact (KIC) person who assisted with the dissemination and collection of the survey to all staff working within the acute general medical wards, geriatric evaluation 
and management or aged care wards, rehabilitation wards, community rehabilitation centers, and continence clinics. They either provided paperbased copies of the survey to respondents or emailed the secure website address to them. The researchers' preferred means of completion were web-based as they were seen to be more time and cost efficient. However, advice obtained from the KICs at each health service was that not all health service staff had ready access to computers and completion rates would be increased if a mixture of both web-based and paper-based surveys was used. By using two different modes of survey completion, the project team reduced coverage error and improved the response rate (Dillman et al., 2009), ensuring that as many people as possible in the target population were able to complete the survey through a mode that was preferable to them. Following this, the KICs assisted with posting back all paper-based completed surveys to the researchers in a prepaid envelope. All surveys were completed anonymously. Whilst the researchers acknowledge that there could be differences between the responses from the two different data collection modes, they are unable to differentiate between those that were completed via the Internet and those that were completed as paper based.

\section{Data analysis}

The survey results were analyzed using SPSS version 17.0. Psychometric evaluations of the internal consistency reliability and construct validity of the survey were conducted. These were also used to aid in the item reduction of the survey. The objective was to develop a reduced-item survey with a stable and interpretable factor structure and with acceptable internal consistency across the survey as well as within the factors.

The construct validity of the survey was determined using exploratory factor analysis. The criteria to indicate the suitability of the data for the factor analysis were Bartlett's test of sphericity of significance and the Kaiser-Meyer-Olkin measure of sampling adequacy of $\geq 0.7$. The extraction of factors was determined by the number of factors with eigenvalues greater than 1. Factors were subjected to direct oblimin rotation (assuming the inter-relatedness of the items and therefore the factors) and interpreted. Cross-loading items in the rotated factor structure were eliminated to increase the stability of the factor structure.

Internal consistency reliability was examined through item-total correlations and Cronbach's $\alpha$ coefficient. Items with item-total correlation $(\alpha)$ coefficients less than 0.3 were considered inappropriate and were deleted from the data prior to factor analysis. Following the factor analysis, Cronbach's $\alpha$ coefficients were found for each factor and for the total of currently remaining items.

\section{Expert and older people consultation}

After the revised tool had been developed, based on the above data analysis, the revised survey, along with a questionnaire about the revised survey, was distributed to six clinical experts and three older people who had been involved in the development and use of the original tool. The revised tool was sent to these nine people for consultation to ensure that it was still an accurate measure of personcentered care. This group of people was asked the following questions:

1. Do you think the revised survey addresses the main aspects of person-centered care?

2. Do you think the revised survey is user-friendly and easy for staff to complete?

3. Do you think the revised survey is easy to understand?

4. Do you think the section titles in the revised survey are suitable?

5. Do you think any of the items that were removed (as a result of the data analyses) should be included in the revised survey? If so, which items and why?

\section{Results}

\section{Participants}

A total of 1,428 surveys were returned, giving an approximate overall response rate of $35.5 \%$. Table 1 shows the demographics of the survey respondents.

One thousand of the questionnaires contained missing data on at least one of the 48 items. This included items for which a participant had responded "don't know," which was not a measurable response and was therefore treated as missing data. For each of the data analyses used, cases with missing items on the relevant items were excluded. However, sampling adequacy was established for this original sample of 428 participants. There were no significant differences between the 428 respondents who answered all questions and the 1,000 respondents who had missing data in relation to the location of their health service (rural or metro), the area they worked in (acute or sub-acute), or their gender. However, there was a difference between the two samples in relation to the disciplines of the respondents $\left(\chi^{2}(5\right.$, $\mathrm{n}=1,428)=19.68, \mathrm{p}<0.01)$. Table 1 shows the demographics of the two groups.

The number of cases available for data analysis increased as items were removed throughout the procedure, resulting in a sample ranging from 428 
Table 1. Demographics of the sample

\begin{tabular}{|c|c|c|c|}
\hline VARIABLE & $\begin{array}{l}\text { ALL RETURNED } \\
\text { SURVEYS } \\
(\mathrm{n}=1,428) \\
\mathrm{N}(\%)\end{array}$ & $\begin{array}{l}\text { SURVEYS WITH } \\
\text { MISSING DATA } \\
(\mathrm{n}=1,000) \\
\mathrm{N}(\%)\end{array}$ & $\begin{array}{l}\text { SURVEYS WITHOUT } \\
\text { MISSING DATA } \\
(\mathrm{n}=428) \\
\mathrm{N}(\%)\end{array}$ \\
\hline \multicolumn{4}{|l|}{ Gender } \\
\hline Male & $171(12)$ & $122(12.2)$ & $49(11.4)$ \\
\hline Female & $1,228(86)$ & $858(85.8)$ & $370(86.4)$ \\
\hline Not stated & $29(2)$ & $20(2)$ & $9(2.1)$ \\
\hline \multicolumn{4}{|l|}{ Discipline } \\
\hline Administration/management & $49(3.4)$ & $40(4.0)$ & $9(2.1)$ \\
\hline Allied health & $469(32.8)$ & $353(35.3)$ & $116(27.1)$ \\
\hline Medical & $67(4.7)$ & $49(4.9)$ & $18(4.2)$ \\
\hline Nursing & $790(55.3)$ & $517(51.7)$ & $273(63.8)$ \\
\hline Other & $20(1.4)$ & $14(1.4)$ & $6(1.4)$ \\
\hline Not stated & $33(2.3)$ & $27(2.7)$ & $6(1.4)$ \\
\hline \multicolumn{4}{|l|}{ Area/program/ward } \\
\hline Community rehabilitation centers & $173(12.1)$ & $146(14.6)$ & $27(6.3)$ \\
\hline Continence clinics & $40(2.8)$ & $30(3.0)$ & $10(2.3)$ \\
\hline General medical & $380(26.6)$ & $255(25.5)$ & $125(29.2)$ \\
\hline Geriatric evaluation and management unit & $254(17.8)$ & $182(18.2)$ & $72(16.8)$ \\
\hline Rehabilitation wards & $356(25)$ & $226(22.6)$ & $130(30.4)$ \\
\hline Other & $206(14.4)$ & $148(14.8)$ & $58(13.6)$ \\
\hline Not stated & $19(1.3)$ & $13(1.3)$ & $6(1.4)$ \\
\hline
\end{tabular}

to 471 participants for the factor analyses and 471 to 1,389 for reliability analyses.

\section{Item analysis and reduction}

The sample was tested for suitability for factor analysis. Bartlett's test of sphericity was significant $(7,841.8, \mathrm{p}<0.001)$ and Kaiser-Meyer-Olkin was satisfactory (0.926), which indicated that the sample was suitable for factor analysis.

Initial examination of the item-total correlation matrix identified ten items with $\alpha$ correlation coefficients less than 0.3 and these were removed. This reduced the 48 -item survey to 38 items.

Principal components analysis on the remaining 38 items suggested an eight-factor solution based on the criterion of eigenvalues exceeding 1 , which explained $60.2 \%$ of the variance. Following this, three cross-loading items were removed as they had a moderate loading $(>0.3)$ on more than one factor and were close in size on each of the factors they loaded on (within 0.15 of each other). A further four items were removed due to low factor loadings $(<0.4)$.

Another principal components analysis with direct oblimin rotation was conducted on the remaining 31 items. The original factor structure was confirmed and the eight-factor solution explained $62.7 \%$ of the variance, indicating satisfactory content validity. Factor 1 (accounting for $29.6 \%$ of the variance) contained four items looking at "involvement in care planning." Factor 2 accounted for $7.6 \%$ of the variance and contained two items (both with factor loadings exceeding 0.8 ) focusing on "finding out goals." Factor 3, which contributes $6.4 \%$ of the total variance, contained seven items about the "supportive working environment." Factor 4 had four items, explaining $4.3 \%$ of the variance. These items addressed the area of "co-ordinated contact." Factor 5 (accounting for $4.1 \%$ of the variance) also had four items which looked at "meeting practical needs" of the service user. Factor 6 explained 3.8\% of the variance with four items focusing on "meeting communication needs." Factor 7 had three items (all with factor loadings $>0.6$ ) looking at issues around "getting to know the individual," and it contributed $3.5 \%$ of the variance. Finally, factor 8 accounted for $3.4 \%$ of the variance and contained three items related to "attitudes toward personcentered care." All of the eight identified factors had good internal consistency, with Cronbach's $\alpha$ coefficients for each factor ranging between 0.56 and 0.85 , given a range of between 0.5 and 0.6 is considered acceptable for preliminary research (Nunally, 1978). Factor loading of each survey item, explained variance, and Cronbach's $\alpha$ coefficients for each factor can be seen in Table 2 .

Of the 17 items that were removed from the original survey, eight items were about attitudes and beliefs rather than practices in person-centered care. Only one of the attitudes and beliefs questions from 


\begin{tabular}{|c|c|c|c|}
\hline SURVEY ITEM & $\begin{array}{l}\text { FACTOR } \\
1\end{array}$ & $\begin{array}{l}\text { FACTOR } \\
2\end{array}$ & $\begin{array}{l}\text { FACTC } \\
3\end{array}$ \\
\hline $\begin{array}{l}\text { Service users and carers have equal say with rest of the team in } \\
\text { development of discharge plan }\end{array}$ & 0.78 & & \\
\hline $\begin{array}{l}\text { Service users have equal say with rest of the team in development } \\
\text { of care plan }\end{array}$ & 0.74 & & \\
\hline My/our care plans are structured around service user's goals & 0.56 & & \\
\hline $\begin{array}{l}\text { We provide services in location that best suits needs/preferences of } \\
\text { service user }\end{array}$ & 0.50 & & \\
\hline I ask service users what their goals are for this admission & & 0.82 & \\
\hline I ask carer(s) what their goals are for this admission & & 0.81 & \\
\hline I am supported to develop skills I need to work with older people & & & -0.81 \\
\hline $\begin{array}{l}\text { I have been exposed to good role models in care for older } \\
\text { people }\end{array}$ & & & -0.80 \\
\hline $\begin{array}{l}\text { The expectations my managers have of me in relation to my work } \\
\text { with older people are communicated clearly and consistently }\end{array}$ & & & -0.78 \\
\hline $\begin{array}{l}\text { Emotional and physical demands of my work are acknowledged } \\
\text { and recognized }\end{array}$ & & & -0.75 \\
\hline $\begin{array}{l}\text { I feel that I work as part of a team with a recognized and valued } \\
\text { contribution }\end{array}$ & & & -0.68 \\
\hline I have been exposed to good environments of care for older people & & & -0.66 \\
\hline I feel that I am able to use my skills to the full in my work with & & & -0.55 \\
\hline
\end{tabular}

older people

Service users are allocated key contact person who is known to the service user and carer(s)

Service user and carer have ready access to the key contact person

If service user makes contact with Health Service, they are

directed to most appropriate service without having to make another call (single point of contact)

After service users are discharged, they receive a follow-up phone call or visit

At this health service, hot food served hot and service users

provided with assistance to eat (if required) while food is still warm

This health service provides adequate transport and parking to ensure access for older service users and their families/carers

This health service ensures that service users' personal privacy is respected

Carers given time and adequate assistance to prepare for discharge

I use interpreters when working with service users whose first

$-0.81$

$-0.80$

0.78

$-0.75$

$-0.68$

$-0.66$

$-0.55$ 


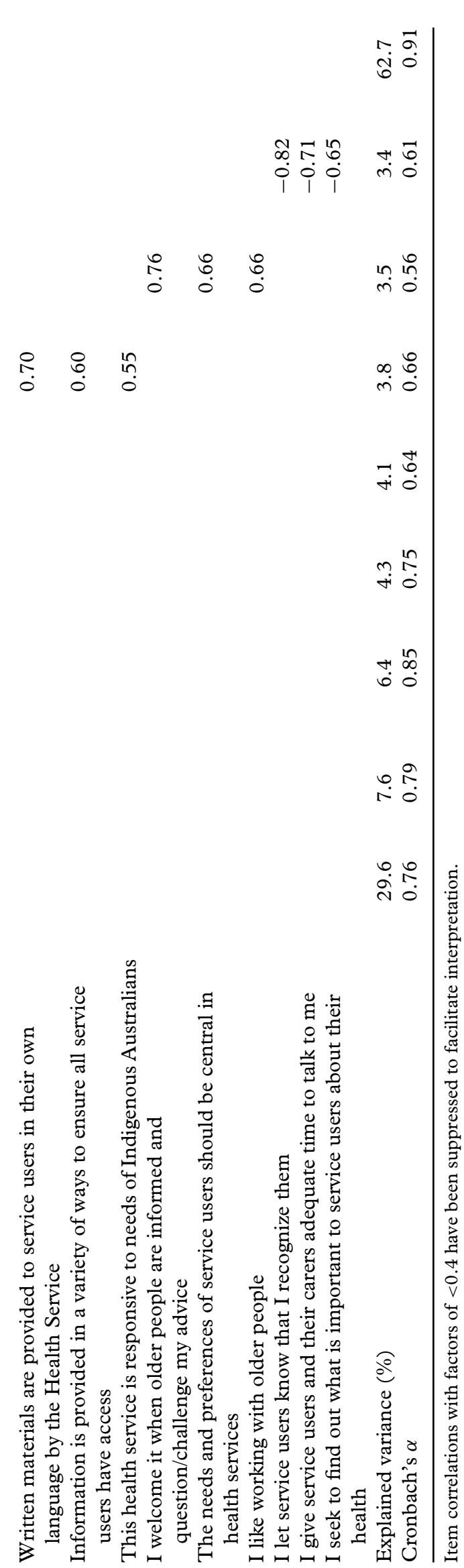

the original survey remained in the revised survey. The items that were removed were across all aspects of person-centered care. Table 3 lists the survey items that were removed.

Finally, internal consistency of the 31-item survey was assessed, yielding a Cronbach's $\alpha$ coefficient of 0.91 , which indicated good internal consistency.

All of the 31 items in the revised survey except for one were related to practice, and therefore used the response format ranging from never to always. This response format was appropriate to use for the one attitude or belief item that remained in the revised survey; therefore, the response format of a 5-point Likert scale, ranging from 1 (never) to 5 (always), was used for all questions in the revised survey.

The revised survey, with 31 items distributed into eight sub-scales, was titled the "Person-Centred Health Care for Older Adults (PCHCOA) Survey" (see Appendix A1 published as supplementary material online attached to the electronic version of this paper at http://journals.cambridge.org/jpg).

\section{Consultation on survey content}

Those who provided feedback (three clinical experts and three older people) felt that the revised survey was easy to understand, user-friendly, and easy for staff to complete, and addressed the main aspects of person-centered care. This indicated that the revised survey had content validity. One respondent suggested that the items that were excluded from the original survey following the factor analysis could still be used in staff training as, even though they are not necessary to have in the revised survey, they are still important aspects of person-centered healthcare.

\section{Discussion}

The "Person-Centred Health Care for Older Adults Survey" appears to be a valid and reliable measure of current practice in person-centered care in the inpatient hospital setting from the point of view of healthcare staff. The original survey was based on the literature and advice from older people, but it had no psychometric evaluation and was considered too lengthy. The revised survey is shorter in length but still appears to measure the same aspects of person-centered care as identified in the literature. The literature review undertaken by NARI identified five principles of person-centered care (Dow et al., 2006). The first principle of getting to know the patient or client as a person is encompassed in the eighth factor of the revised survey, "getting to know the individual." "Finding out goals" and "involvement in care planning" 
Table 3. Survey items that were removed in the development of the Person-Centred Health Care for Older Adults Survey

ITEMS REMOVED FROM SURVEY

It is important to get to know each service user as an individual (e.g. their medical history, social supports, pre-morbid status)

It is important to find out how the service user and carer feel about this episode of care (e.g. worried about surgery, or how they will manage when discharged)

I listen carefully to what service users say

I find out what name the service user prefers to be called

Healthcare should be in an equal partnership between the service user and provider

If provided with options, service users are usually able to make a choice that is best for them

Services should be accessible to service users of all ages, abilities, from all culturally and linguistically diverse

(CALD) backgrounds, and indigenous Australians

Services should be available at times and in places that suit service users and their families/carers

This health service environment is designed to meet the needs of people with physical and cognitive disabilities

We provide services at times that suit service users (including after hours and on weekends)

Health services should ensure that the service user has the information they need to understand what is happening to them throughout their whole care experience

The health service in which I work is responsive when service users request information about their health condition and/or care plan

The health service in which I work is responsive when carers request information about the service user's health condition and/or care plan (with the client's request)

Service users are given information to enable them to make an informed choice about discharge or transfer from my service

I feel that working with older people is valued within this health service

Healthcare should be a collaborative partnership between service user and provider

Our practice is well coordinated and there is minimal duplication when referring clients from one part of the health service to another and to community services
TYPE OF ITEM SURVEY SECTION

Attitude/belief

Getting to know the older service user

Attitude/belief

Getting to know the older service user

Practice

Practice

Attitude/belief

Getting to know the older service user Getting to know the older service user Sharing power and responsibility

Attitude/belief

Sharing power and responsibility

Attitude/belief

Service flexibility and accessibility

Attitude/belief

Service flexibility and accessibility

Practice

Service flexibility and accessibility

Practice

Attitude/belief

Service flexibility and accessibility

Making sense of services for the older service user

Practice

Practice

Practice

Making sense of services for the older service user

Making sense of services for the older service user

Making sense of services for the older service user

Practice

Attitude/belief

The working environment facilitates person-centered practice

Practice capture the second principle identified in the literature of sharing of power and responsibility. The sixth sub-scale in the revised survey, "meeting communication needs" addresses the principle of accessibility and flexibility. The principle of coordination and integration is covered in the subscale "co-ordinated contact." The final principle, having an environment that is conducive to personcentered care, is captured by "supportive working environment," "meeting communication needs," and "attitudes toward person-centered practice." However, as well as measuring the aspects of person-centered care identified in the literature, the
PCHCOA survey is unique and measures aspects of person-centered care that are important to older people themselves. This is addressed in the subscale "meeting practical needs" and captures the items in the original "benchmarking person-centred care" survey that addressed concerns expressed by older people. Furthermore, items within each factor seemed to be conceptually consistent allowing for clear interpretations of the factors.

Since the original review, there has been considerable international development in the concept of person-centered care including in the hospital setting (Huby et al., 2007; Olsson et al., 
2009; Redfern et al., 2009; Bamm et al., 2010; Flynn et al., 2010; Poochikian-Sarkissian et al., 2010; Doig et al., 2011; McMurray et al., 2011). In the main, this more recent research supported the findings of the original review and the survey items derived from that review, suggesting that the PCHCOA is in line with current international research into person-centered healthcare. Studies of integrated care have found that individualized goal setting and well-coordinated care are effective in improving outcomes for patients (Olsson et al., 2009; Redfern et al., 2009). Other aspects of person-centered care identified as important were exposure to good role models (Flynn et al., 2010; PCHCOA, item 3.2), a partnership approach in the management of Chronic Obstructive Pulmonary Disease (COPD; PCHCOA Sections 1, 2, 3, and 6; Ingadottir and Jonsdottir, 2010), and the organizational context supporting person-centered care (PCHCOA, Section 3; Huby et al., 2007), all of which are included in the PCHCOA survey. The one area identified in the more recent research that was not specifically identified in the survey was the importance of patient education (PoochikianSarkissian et al., 2010). However, if all other aspects of care identified in the survey were being practiced, patient education would be addressed as part of care planning, goal setting, meeting communication needs, and getting to know the individual (PCHCOA, sections 1,2,6, and 8).

Since the development of the "benchmarking person-centred care" survey, there have also been other tools developed that measure person-centered care in Australia, Europe, and the United States, including, but not limited to, the Person-Centred Care Assessment Tool (P-CAT; Edvardsson et al., 2009b), the Person-Directed Care measurement tool (White et al., 2008), the Person-Centred Climate Questionnaire-patient version (Edvardsson et al., 2008), and the Person-Centred Climate Questionnaire-staff version (Edvardsson et al., $2009 b)$. More information about these tools is given in Table 4. However, these have been developed for different settings, for use with different audiences, or measure different aspects of person-centered care from the current tool. The Person-Centred Climate Questionnaire-patient version (Edvardsson et al., 2008) measures person-centered care from the point of view of the patient. The P-CAT (Edvardsson et al., 2009a) and the Person-Directed Care measurement tool (White et al., 2008) measure staff perceptions of person-centered care in long-term care, which is a qualitatively different environment to a hospital setting, requiring different person-centered care practices. Unlike care homes, where the older person is a permanent resident, hospital staff-patient relationships are generally short term and focused on management of acute or chronic illness and discharge planning. Although there are some areas of overlap, the PCHCOA survey focuses specifically on healthcare and includes practices that are specific to a health environment, such as development of a discharge plan (PCHCOA, item 1.2), location of healthcare (item 1.4), goals for this admission (items 2.1 and 2.2), and follow-up after admission (item 4.4). The most similar tool was the Person-Centred Climate Questionnaire-staff version. However, this tool measured staff perceptions of the personcenteredness of the hospital environment as opposed to the attitudes and care practices of staff. Although we acknowledge that this is an important component of person-centered care (included in Section 3 of PCHCOA), we wanted a measure that would give staff direction about aspects of care that they had direct control over as well as organizational factors.

Eight of the 17 items that were removed from the original survey were attitudes and beliefs questions. Only one of the attitudes and beliefs questions from the original survey remains in the revised PCHCOA survey. The attitudes and beliefs questions in the original survey generally received a very high response rate of usually or always. They indicated that healthcare staff believed that personcentered care was important; however, they did not provide a true indication of whether personcentered practices were actually occurring within a health service. The removal of these items suggests the PCHCOA is now a more accurate measure of person-centered care practices. The other nine items removed from the original survey were spread across all aspects of person-centered care identified in the literature. This indicates that all aspects of person-centered care identified in this literature which formed the basis of this survey are important; however, it was not necessary to have as many items for each factor as was in the original survey.

There were limitations to this study. Although the survey asks questions about person-centered practice, it may have a social desirability bias because it only looks at what staff perceive. Future studies could combine this survey with an approach similar to that used by Wellard et al. (2003), where they compared the findings of focus group discussions with staff with observations made on a ward by a trained researcher, looking at whether there were any discrepancies between participants' beliefs about practice and their actual practice.

Furthermore, this survey does not measure service user perceptions about the care they receive. It has items about aspects of person-centered healthcare that older people themselves believe are important, but it only measures staff perceptions of 


\begin{tabular}{|c|c|c|c|c|c|}
\hline INSTRUMENT & PURPOSE OF TOOL & RESPONDENT & $\begin{array}{l}\text { CLINICAL } \\
\text { SETTING }\end{array}$ & RESPONSE SCALE & $\begin{array}{l}\text { SUBSCALES OR FACTORS } \\
\text { AND NUMBER OF ITEMS }\end{array}$ \\
\hline $\begin{array}{l}\text { Person-centred Care } \\
\text { Assessment Tool } \\
\text { (P-CAT; Edvardsson } \\
\text { et al. 2009a) }\end{array}$ & $\begin{array}{l}\text { Aims to measure the extent to } \\
\text { which staff rate their aged care } \\
\text { setting to be person-centered }\end{array}$ & Staff & $\begin{array}{l}\text { Long-term aged care } \\
\text { setting }\end{array}$ & $\begin{array}{l}\text { 5-point Likert scale: } \\
\text { 1= “disagree } \\
\text { completely," } 5=\text { "agree } \\
\text { completely" }\end{array}$ & $\begin{array}{l}\text { 13-items, } 3 \text { sub-scales: extent of } \\
\text { personalizing care ( } 7 \text { items), } \\
\text { amount of organizational } \\
\text { support ( } 4 \text { items), degree of } \\
\text { environmental accessibility } \\
\text { ( } 2 \text { items) }\end{array}$ \\
\hline $\begin{array}{l}\text { Person-Directed Care } \\
\text { measurement tool } \\
\text { (White et al., 2008) }\end{array}$ & $\begin{array}{l}\text { To assess person-directed care } \\
\text { practices in long-term care }\end{array}$ & Staff & Long-term care & $\begin{array}{l}\text { 5-point Likert scale: } \\
1=\text { "very few or none" } \\
\text { or "rarely or none of the } \\
\text { time" and } 5=\text { "all or } \\
\text { almost all" or "all or } \\
\text { almost all of the time" }\end{array}$ & $\begin{array}{l}8 \text { factors ( } 5 \text { related to } \\
\text { person-directed care and } 3 \\
\text { related to environmental } \\
\text { support): knowing the person } \\
\text { ( } 7 \text { items), comfort care } \\
\text { ( } 8 \text { items), autonomy ( } 7 \text { items), } \\
\text { personhood ( } 7 \text { items), support } \\
\text { relations ( } 6 \text { items), your work } \\
\text { with residents ( } 5 \text { items), } \\
\text { personal environment for } \\
\text { residents ( } 4 \text { items), } \\
\text { management/structure ( } 6 \text { items) } \\
50 \text { items in total }\end{array}$ \\
\hline $\begin{array}{l}\text { Person-centred Climate } \\
\text { Questionnaire-patient } \\
\text { version (Edvardsson } \\
\text { et al., 2008) }\end{array}$ & $\begin{array}{l}\text { Measuring the extent to which the } \\
\text { climate (physical and } \\
\text { psychosocial environment) is } \\
\text { person-centered or supports the } \\
\text { patient as person and places } \\
\text { their needs and expectations at } \\
\text { the center of care. }\end{array}$ & Patient & $\begin{array}{l}\text { Inpatient setting } \\
\text { (acute and } \\
\text { sub-acute) }\end{array}$ & $\begin{array}{l}\text { 7-point Likert scale; } \\
1=\text { No, I disagree } \\
\text { completely, } 7=\text { Yes, I } \\
\text { agree completely }\end{array}$ & $\begin{array}{l}17 \text { items with } 3 \text { factors: safety } \\
\text { (10 items), everydayness } \\
\text { (4 items) and hospitality } \\
\text { (3 items) }\end{array}$ \\
\hline $\begin{array}{l}\text { Person-centred Climate } \\
\text { Questionnaire-staff } \\
\text { version (Edvardsson } \\
\text { et al., 2009b) }\end{array}$ & $\begin{array}{l}\text { Measures staff perceptions of the } \\
\text { person-centeredness of the } \\
\text { hospital environment as } \\
\text { opposed to the care. Based on } \\
\text { the theoretical framework that } \\
\text { supportive environments are } \\
\text { places that maintain } \\
\text { personhood of the individual } \\
\text { through providing a } \\
\text { person-centered climate }\end{array}$ & Staff & Inpatient setting & $\begin{array}{l}\text { 6-point Likert scale; } \\
1=\text { No, I disagree } \\
\text { completely, } 6=\text { Yes, I } \\
\text { agree completely }\end{array}$ & $\begin{array}{l}14 \text { items with } 3 \text { factors: climate of } \\
\text { safety ( } 5 \text { items), a climate of } \\
\text { everydayness ( } 5 \text { items), a } \\
\text { climate of community ( } 4 \text { items) }\end{array}$ \\
\hline
\end{tabular}


whether this is happening, not whether the service user perceives it to be happening. An accompanying survey that measures the service users' perceptions about the level of person-centered care in relation to staff practice would be a useful tool to develop, similar to those developed by Edvardsson and colleagues $(2008 ; 2009 b)$ in Sweden that measure the person-centered care environment.

Future research on use of this survey could include its use as a measure of person-centered healthcare within the hospital setting overall, as well as exploring different aspects of personcentered healthcare if the tool is broken down into sub-scales. Health services potentially could use it to benchmark themselves against other health services, as well as identify areas of person-centered healthcare where they are performing well. Used in this way, the survey could assist in identifying areas of person-centered healthcare that require improvement in the service as a whole and, as a result, may assist in identifying areas of need for staff training and improving care for older people.

In addition, future studies could examine the test-retest reliability of the PCHCOA survey and its ability to be used as a pre-post measure of personcentered care in the hospital setting. Whilst the data in this study were collected in 2005, the updated literature review suggests that the survey items are consistent with current conceptual development in this area. Finally, the large number of missing data resulting in a loss of sample size may have impacted on the results. Even though there were 1,428 survey respondents, some items had a sample as small as 428. However, there was only one significant difference between the groups who completed all items and those who did not, with nurses being more likely to complete all items than allied health professionals.

\section{Conclusion}

The results indicate that the PCHCOA survey is a psychometrically valid and reliable measure of staff perceptions of person-centered healthcare for use in hospital settings. The PCHCOA survey is a shorter, more user-friendly survey than the original that can be used by health services to benchmark their person-centered practice within the hospital setting and identify areas of person-centered healthcare for improvement.

\section{Conflict of interest}

None.

\section{Description of authors' roles}

B. Dow designed the study, supervised the data collection, assisted with data analysis, and wrote the paper. M. Fearn collected data, assisted with data analysis, and wrote the paper. B. Haralambous, J. Tinney and K. Hill assisted with data collection and writing of the paper. S. Gibson assisted with data analysis and writing of the paper.

\section{Acknowledgments}

This work was supported by the Ambulatory and Continuing Care Division, Victorian Government Department of Health, Victoria, Australia.

The project team wish to thank the Key Implementation Contacts for their assistance with dissemination and collection of the surveys; the staff at the 17 participating Victorian Health Services who completed the survey; the Project Advisory Committee and the Consumer Reference Group for their input in the development of the original survey; and Ms Esther Cramer and Ms Maggie Yu who assisted with data analysis during their psychology placement.

\section{References}

Australian Institute of Health and Welfare (2009). Australian Hospital Statistics 2007-08. Health services series no. 33. Cat. no. HSE 71. Canberra: AIHW.

Bamm, E. L., Rosenbaum, P. and Stratford, P. (2010). Validation of a measure of processes of care for adults: a measure of client-centred care. International fournal for Quality in Health Care, 22, 302-309.

Bridges, J., Flatley, M. and Meyer, J. (2009). Older people's and relatives' experiences in acute care settings: systematic review and synthesis of qualitative studies. International fournal of Nursing Studies, 47, 89-107.

Department of Economic and Social Affairs: Population Division (2002). World Population Ageing: 1950-2050. New York: United Nations Publications.

Dillman, D. A., Smyth, J. D. and Chritian, L. M. (2009). Internet, Mail and Mixed-mode Surveys: The Tailored Design Method. Hoboken, NJ: John Wiley \& Sons Inc.

Docherty, B. (2000). Using triangulation in health care research. Professional Nurse, 16, 926-927.

Doig, E., Fleming, J., Kuipers, P., Cornwell, P. and Khan, A. (2011). Goal-directed outpatient rehabilitation following TBI: a pilot study of programme effectiveness and comparison of outcomes in home and day hospital settings. Brain Injury, 25, 1114-1125.

Dow, B., Haralambous, B., Bremner, F. and Fearn, $M$. (2006). What is person-centred health care? A literature review. National Ageing Research Institute Report to Department of Human Services, Melbourne.

Edvardsson, D., Sandman, P. O. and Rasmussen, B. (2008). Swedish language Person-centred Climate 
Questionnaire-patient version: construction and psychometric evaluation. Fournal of Advanced Nursing, 63, 302-309.

Edvardsson, D., Fetherstonhaugh, D., Nay, R., Gibson, S., Sandman, P. O. and Rasmussen, B. (2009a). Development and initial testing of the Person-centered Care Assessment Tool (P-CAT). International Psychogeriatrics, 22, 101-108.

Edvardsson, D., Sandman, P. O. and Rasmussen, B. (2009b). Construction and psychometric evaluation of the Swedish language Person-centred Climate Questionnaire-staff version. Fournal of Nursing Management, 17, 790-795.

Flynn, D. S. et al. (2010). Raising the bar of care for older people in Ontario emergency departments. International fournal of Older People Nursing, 5, 219-226.

Harkness, J. (2005). What is Patient-Centred Health Care? London: International Alliance of Patients' Organizations.

Huby, G., Brook, J. H., Thompson, A. and Tierney, A. (2007). Capturing the concealed: interprofessional practice and older patients' participation in decision-making about discharge after acute hospitalisation. Fournal of Interprofessional Care, 21, 55-67.

Ingadottir, T. S. and Jonsdottir, H. (2010). Partnership-based nursing practice for people with chronic obstructive pulmonary disease and their families: influences on health-related quality of life and hospital admissions. fournal of Clinical Nursing, 19, 2795-2805.

Law, M., Baptiste, S. and Mills, J. (1995). Clientcentred practice: what does it mean and does it make a difference? Canadian fournal of Occupational Therapy, 62, 250-257.
McMurray, A., Chaboyer, W., Wallis, M., Johnson, J. and Gehrke, T. (2011). Patients' perspectives of bedside nursing handover. Collegian, 18, 19-26.

National Health and Medical Research Council (1999). NHMRC Standards and Procedures for Externally Developed Clinical Practice Guidelines. Canberra: NHMRC.

Nunally, J. C. (1978). Psychometric Theory. New York: McGraw-Hill.

Olsson, L. E., Hansson, E., Ekman, I. and Karlsson, J. (2009). A cost-effectiveness study of a patient-centred integrated care pathway. Fournal of Advanced Nursing, 65, 1626-1635.

Poochikian-Sarkissian, S., Sidani, S., Ferguson-Pare, M. and Doran, D. (2010). Examining the relationship between patient-centred care and outcomes. Canadian Fournal of Neuroscience Nursing, 32, 14-21.

Redfern, J., Briffa, T., Ellis, E. and Freedman, S. B. (2009). Choice of secondary prevention improves risk factors after acute coronary syndrome: 1-year follow-up of the CHOICE (Choice of Health Options In prevention of Cardiovascular Events) randomised controlled trial. Heart, $95,468-475$.

Victorian Government Department of Human Services (2003). Improving Care for Older People: A Policy for Health Services. Melbourne: DHS.

Wellard, S., Lillibridge, J., Beanland, C. and Lewis, $M$. (2003). Consumer participation in acute care settings: an Australian experience. International fournal of Nursing Practice, 9, 255-260.

White, D. L., Newton-Curtis, L. and Lyons, K. S. (2008). Development and initial testing of a measure of person-directed care. Gerontologist, 48, 114-123. 